\title{
A RESPONSABILIDADE CIVIL DO MUNICÍPIO DE SANTO ANTONIO DE JESUS-BA EM RELAÇÃO AOS ANIMAIS DOMÉSTICOS ABANDONADOS
}

\section{CIVIL RESPONSIBILITY OF THE SANTO ANTÔNIO DE JESUS-BA MUNICIPALITY IN RELATION TO ABANDONED DOMESTIC ANIMALS}

Adrielli dos Santos Oliveira Andrade ${ }^{1}$ Aline Passos Santos ${ }^{2}$

\begin{abstract}
Estudos sobre a defesa dos animais tem ganhado grande repercussão mundial, afinal são seres vivos que dependem do homem para ter seus direitos atendidos. Os animais são detentores de direitos que aos poucos estão sendo positivados em legislações específicas como forma de garantir o bem-estar destes. Essa pesquisa tem como objetivo geral analisar a responsabilidade civil do município de Santo Antônio de Jesus-BA em relação aos animais domésticos abandonados e verificar quais ações estão sendo implementadas para proteção desses seres. Em relação aos procedimentos metodológicos, foi desenvolvida uma pesquisa bibliográfica e documental acerca das leis e projetos de leis que protegem os animais abandonados. Além disso, foi realizada uma análise documental na ONG Amo Animais, na Secretaria de Meio Ambiente, Vigilância Sanitária e no Ministério Público, em Santo Antônio de Jesus-BA. Nesse diapasão verificou-se que o município responde de maneira objetiva pelas suas condutas, desde que gerem algum dano, devendo ter sua atuação pautada na efetivação e implementação de políticas públicas que visem à conscientização da população, criação de abrigos públicos que busquem dar qualidade de vida a esses seres indefesos por ser medida de saúde pública.
\end{abstract}

Palavras-chave: Direito dos Animais. Meio Ambiente. Direito Ambiental. Saúde Pública.

Studies on the defense of animals have gained great repercussion worldwide, after all they are living beings that depend on men to have their rights safeguarded. Animals are right holders that are gradually being included in specific legislation as a way to guarantee their welfare. This research has as general objective to analyze the civil responsibility of the municipality of Santo Antônio de Jesus-BA in relation to abandoned domestic animals, and verify what actions are being implemented to protect these beings. Regarding methodological procedures, a bibliographical and documentary research was carried out on the laws and draft laws that protect abandoned animals. In addition, a documentary analysis was conducted at the NGO Amo Animais, at the Secretariat of Environment, Sanitary Surveillance and at the Public Ministry, in Santo Antônio de Jesus-BA. In this context, it was verified that the municipality responds in an objective way for its conduct, since it generates some damage, and its action must be based on the implementation of public policies aimed at raising awareness of the population, creating public shelters that seek to provide quality life to these defenseless beings because it is a measure of public health.

Keywords: Animal Rights. Environment. Environmental Law. Public Health.

Recebido: 05/03/2019

Aceito: $20 / 06 / 2019$

\footnotetext{
1Bacharela em Direito pela Faculdade de Ciências e Empreendedorismo, Santo Antônio de Jesus-BA. http://lattes.cnpq.br/0247971833333056. Email:adrielli@gmail.com

${ }^{2}$ Mestranda em Desenvolvimento Regional e Meio Ambiente na Faculdade Maria Milza -FAMAM. Santo Antônio de Jesus-BA. http://lattes.cnpq.br/3086938617488779. alinepassosadv@gmail.com
} 


\section{INTRODUÇÃO}

A defesa dos animais tem ganhado grande repercussão no Brasil, afinal são seres vivos que dependem do Homem para ter seus direitos atendidos, e para isso, os entes federativos devem atuar em conjunto para garantir o bem-estar destes. Atualmente tem-se buscado a desconstituição da possibilidade dos animais não humanos não serem sujeitos de direitos e para isto não se deve observar se estes são capazes ou não de raciocinar e sim a possibilidade de terem sentimentos afinal são seres vivos sensitivos, porém não conseguem se defender sozinhos.

Esses seres não humanos são detentores de direitos que aos poucos estão sendo positivados em legislações específicas como forma de garantir mais efetividade ao que já é previsto na Constituição Federativa da República do Brasil de 1988. A proteção dos animais se tornou um assunto tão relevante e cobrado pela população que a União, Estado e o Município tem procurado responder através de ações que visem o bem-estar animal ou ao menos a diminuição do sofrimento.

O primeiro código civil brasileiro a trazer a situação jurídica dos animais no Brasil, foi o de 1916 mas nesse período os animais eram considerados como coisas. Em 1924, o decreto $n^{\circ} 16.590$, começou a coibir a crueldade contra os animais. Sendo reforçado com o Decreto-Lei $n^{\circ} 24.645$ de 1934 , art. $1^{\circ}$, editado por Getúlio Vargas, dispondo que os animais passaram a ter o direito de serem tutelados pelo Estado, sendo também estabelecido algumas medidas de proteção e penas para quem causasse maustratos aos animais.

Em conjunto, a Constituição da República Federativa do Brasil de 1988, artigo 225, §1, VII, corrobora nesse sentido, apontando ao poder público a função de proteger a fauna e a flora (BRASIL, 1988).

Em relação aos maus tratos, o art. 32 da Lei no 9.605/98, estabelece que é crime praticar ato de abuso e maus tratos aos animais silvestres, domésticos e domesticados, sendo que tanto as pessoas jurídicas quanto as pessoas físicas poderão ser responsabilizadas administrativa, civil e penalmente, quando cometer alguma conduta que cause lesões ao meio ambiente (BRASIL, 1998).

No ano de 2017 houve a aprovação da lei $n^{\circ} 13.426$, de alcance nacional, que dispõe sobre a política de controle de natalidade de cães e gatos com o intuito de reduzir a taxa populacional dos animais não-domiciliados (BRASIL,2017). Essa lei prevê a realização de campanhas educativas que propicie à população a noção de ética sobre a posse responsável.

Assim, vê-se que a própria Constituição e as leis dispõem sobre a temática referente à proteção dos animais, no entanto, mesmo assim, os animais estão esquecidos, desamparados de cuidados e abandonados, gerando aumento de cães nas vias públicas, aumento de doenças, e violação do que está disposto em todas as leis.

Deve-se considerar ainda o relatório de Brambell (1965) que define as "cinco liberdades" aos animais e as condições para alcançá-lo, como liberdade de sede, fome e má-nutrição, liberdade de dor, ferimentos e doença, liberdade de desconforto, liberdade para expressar comportamento natural e liberdade de medo e de estresse.

Além disso, a Declaração de Cambridge sobre a Consciência em Animais Humanos e NãoHumanos, promulgada em 7 de julho de 2012, prevê que os animais não-humanos, mesmo sem a presença do neocórtex podem sentir os estados afetivos e esses substratos neurológicos geram a consciência e comportamentos intencionais, permitindo assim, reconhecer que estes são seres sencientes.

Atualmente, a Lei $\mathrm{n}^{\circ} 8$ de 03 de março 2017, que entrou em vigor em 01 de maio de 2017 em Portugal, além de estabelecer um estatuto jurídico dos animais (EJA), alterando o Código Civil, o Código de Processo Civil e o Código Penal, instituiu novas obrigações e implicações, para quem tem animais de estimação ao seu cuidado. Em seu artigo $201 .^{\circ}$-B os animais são seres vivos dotados de sensibilidade e, portanto, é objeto de proteção jurídica em virtude da sua natureza. Dentre as inovações desta lei, os animais de companhia havidos ao tempo da celebração do casamento não entram na comunhão dos bens, ficando inseridos na lista de bens incomunicáveis do artigo $1788 .^{\circ}$ do Código Civil. 
Desse modo, esta pesquisa justifica-se pelo aumento indiscriminado de animais abandonados na cidade de Santo Antonio de Jesus-Ba, visto que, atualmente, não se têm nenhuma instituição pública que os abrigue, proteja ou cuide, assim a população santoantoniense desconhece o órgão competente para atuar em casos de abandono, atropelamento, enfermidades, maus tratos ou outras situações em que os animais são vítimas.

Esse estudo se mostra relevante vez que tem importância científica quando aponta a deficiência de estudo na área, sendo necessário demonstrar que os animais abandonados e doentes merecem cuidados e que o Estado e o Município têm o dever de garantir esse direito. No que tange à relevância social visto que os animais abandonados podem transmitir raiva, leishmaniose, ou outras enfermidades se não cuidados, demandando ações de políticas públicas garantindo assim que os direitos dos animais e da população sejam alcançados.

A pesquisa traz contribuição para o Município de Santo Antonio de Jesus vez que pretende apontar a responsabilidade deste para que o mesmo tome a iniciativa de incrementar ou instituir alguma ação em prol destes seres indefesos, com o intuito de modificar a atual realidade do município. A escolha do tema se deu devido à existência da ONG Amo Animais e sua atuação no município, e também ao observar a falta de cuidado e o aumento do número de animais abandonados nas ruas e rodovias da cidade.

Para demonstrar a carência de estudos nessa área foi realizado uma pesquisa na base de dados Scientifie Electrone Library Online (SCIELO), no dia 07 de julho de 2017, e encontrado 10229 resultados quando pesquisado a palavra animais, e apenas 3 resultados quando pesquisado pelas palavras Animais and Abandonados em todos os títulos. Restando comprovado a necessidade e importância da realização desse estudo, por que com o passar dos dias a população de animais abandonados aumenta e nenhuma mudança é realizada para alterar essa realidade, como por exemplo, a construção de abrigos públicos para dar acolhimento a estes seres.

Assim, o questionamento que orienta este estudo é quais são as medidas adotadas pelo município de Santo Antônio de Jesus-Ba para amparar os animais domésticos abandonados. Desse modo, o presente artigo, tem como objetivo analisar a responsabilidade civil do município em relação aos animais domésticos abandonados. Como objetivos específicos, a pesquisa visa identificar quais ações são desenvolvidas no município para a proteção dos animais abandonados na cidade de Santo Antônio de Jesus.

\section{METODOLOGIA}

A metodologia utilizada neste estudo foi a revisão bibliográfica, além da análise de leis e projetos de leis que agem em defesa dos animais urbanos abandonados. Utilizou-se também a análise documental na Secretaria de Meio Ambiente, Vigilância Sanitária, no Ministério Público da cidade e na Organização Não Governamental (ONG)Amo Animais.

\section{EVOLUÇÃO DOSDIREITOSDOSANIMAIS NATUREZAJURÍDICADOSANIMAIS}

Em consequência do processo histórico jurídico, e em razão do antropocentrismo, o direito civil clássico adotou a Teoria do Direito, apontando que os animais não humanos deveriam ser tratados como "coisas", sendo então, analisados conforme o direito privado.

Nas palavras de Arnoldo Wald (1990) apud Fauth (2015) direitos reais são as normas que regulam "as relações jurídicas referentes às coisas suscetíveis de apropriação, estabelecendo um vínculo imediato e direto entre o sujeito ativo ou titular do direito e a coisa sobre a qual o direito recai e criando um dever jurídico para todos os membros da sociedade."

Cristiano Chaves (2013), conceitua que "o direito das coisas regula o poder do homem sobre certos 
bens suscetíveis de valor e os modos de sua utilização". Com isso, o direito das coisas representam um conjunto de normas que regulam as relações jurídicas referentes às coisas suscetíveis de apropriação pelo homem.

No mesmo sentido, o artigo 82 do CC assinala que são considerados móveis todos os bens suscetíveis de movimento próprio, ou de remoção por força alheia, e o artigo 1.228 do CC aponta que a faculdade de usar, gozar e dispor da coisa é do proprietário do bem, considerando assim os animais como "coisas". Porém, o exercício desse direito não é livre e ilimitado, devendo ser exercido em conformidade com $\S 1^{\circ}$ do artigo 1.228 e em consonância com os preceitos constitucionais.

Esse entendimento que considera os animais como "coisa" é adotada desde a época de Descartes, e até pouco tempo considerada no âmbito jurídico. Percebe-se, que isto vai de encontro ao que prevê a Constituição Federal de 1988, pois em seu artigo $225, \S 1^{\circ}$, VII, veda práticas cruéis, garantindo direitos subjetivos aos animais, e desta forma reconhece a condição de serem objetos de direito, titulares de uma situação jurídica. O direito é um processo que se mantém em contínua reconstrução e evolução, e observado que tanto os animais humanos quanto os não humanos são seres igualmente sencientes, não devendo considerar que estes se enquadrem no status jurídico de "coisa".

O Brasil, Estado Democrático de Direito na República Federativa, estabelece no artigo $5^{\circ}$ da CF, os direitos da personalidade, as garantias fundamentais, direitos e deveres individuais, desta forma, somente as pessoas seriam consideradas como sujeitos de direitos. Entretanto, alguns direitos surgem a partir de outros fatos jurídicos, nascendo também outros sujeitos de direito.

Sendo assim, o Projeto de Lei n 6.799/2013 objetiva retirar os animais da condição de "coisa", afirmando os direitos dos animais e sua proteção, visando construir uma sociedade mais consciente e solidária, que reconheça a personalidade própria dos animais. No artigo $3^{\circ}$ do referido decreto, os animais domésticos e silvestres passam a possuir a natureza jurídica sui generis, devendo ser considerados sujeitos de direitos despersonificados, podendo gozar e obter a tutela jurisdicional em caso de violação.

Existe também o projeto de Lei 3.670/15, aprovado pela Comissão de Constituição e Justiça e de Cidadania (CCJ), que estabelece novo estatuto dos animais, deixando de ser considerados como "coisa", mas como bens móveis, visto que outros países já avançaram em relação a isso. Com essa alteração, os animais passam a ser bens especiais, por serem considerados seres sencientes.

\section{ANIMALDOMÉSTICO}

Todos os seres vivos que pertencem ao reino Animalia, ou seja, animais. Este grupo é amplo e os todos os seres humanos fazem parte dele compartilhando características, como por exemplo, ter mobilidade própria. A zoologia é a ciência que estuda os animais, classificando estes pela sua estrutura, tipo de alimentação ou pelo tipo de reprodução, sendo esta classificação considerada mais complexa. A classificação mais prática é que divide os animais em selvagens e domésticos.

Os cachorros, gatos e alguns tipos de pássaros são os mais habituais dentre os animais considerados domésticos, sendo também classificados como "bicho de estimação". Destes, o cachorro tem mais destaque, pois há maior vínculo com o ambiente familiar, e em alguns casos, os cachorros auxiliam os seres humanos, como é o caso dos cães guias e os cães terapia.

O conceito animal de estimação tem sido ampliado com o passar do tempo, devido a alguns animais considerados selvagens conseguir conviver com o ser humano, como é o caso das cobras. Já os animais domésticos são aqueles que possuem características adequadas para a convivência com os seres humanos necessitando de cuidados especiais de acordo com cada espécie

De acordo com o IBAMA (2011), os animais domésticos são todos aqueles animais pertencentes às espécies que originalmente possuíam populações em vida livre e que acompanharam a evolução e o deslocamento da espécie humana pelo planeta e que por ela foram melhorados do ponto de vista genético e zootécnico ao ponto de viverem em estreita dependência ou interação com comunidades ou 
populações humanas.

O Instituto Brasileiro de Geografia e Estatística (IBGE), realizou em 2013, a Pesquisa Nacional de Saúde (PNS 2013), e apontou que 44,3\% dos domicílios do país possuem pelo menos um cachorro. Estimando que a população de cachorros em domicílios brasileiros é de 52,2 milhões. Esses dados assinalam que, no Brasil, existem mais cachorros de estimação do que crianças.

\section{RESPONSABILIDADE CIVIL, ADMINISTRATIVA E PENAL DO MUNICÍPIO EM CASO DE ANIMAIS DOMÉSTICOSABANDONADOS}

A federação brasileira é um modelo de organização político-administrativa do Estado que tem como características a descentralização, soberania e autonomia entre si. Com isso, de acordo com o art. $1^{\circ}$ da Constituição Federal, os componentes do Estado Federal têm os seguintes atributos: auto-organização, autoadministração e autogoverno.

A auto-organização, disposto no art. 25 da CF, é a capacidade que os entes federativos têm de definirem sua própria organização e estrutura. A autoadministração, art. $25 \S 1^{\circ}$ da CF, portanto os Estados têm competências legislativas e não-legislativas próprias. E por fim, o autogoverno que permite que os Estados estruturem seu poder.

E é por isso e com fulcro no art. 30, I e II da CF que os municípios possuem competência para legislar sobre assuntos relevantes aos interesses de cada lugar e região e até de suplementar às leis federais e estaduais.

Entre essas competências está a de proteger o meio ambiente e combater a poluição, preservar a floresta, fauna e flora, como prevê o art. 23, VI e VII da CF (BRASIL, 1988). Importante ainda conceituar a fauna como sendo "A fauna representa todo o conjunto de espécies animais, que tem funções reguladoras extremamente importantes nos ecossistemas, especialmente na cadeia alimentar."(Ecodebate, 2011), incluindo assim, todos os animais abandonados.

Nesse sentido, importante ressaltar que existem alguns princípios que norteiam a validade das normas que protegem os animais, e segundo Heron Santana Gordilho (2008) apud Almeida (2013) "o princípio fundamental da teoria abolicionista é que em hipótese alguma os interesses fundamentais dos animais devem ser negligenciados, mesmo que isso possa trazer benefícios para os homens".

Dentre esses princípios estão, o princípio da subsistência ou estabilidade que assegura que o animal deve ser protegido, garantindo-lhe a vida, a qualidade de vida e todas as condições necessárias para sua sobrevivência. O princípio do respeito integral ou absoluto que leva em consideração as questões éticas, considerando que o homem cuida do animal para que não cause nenhum sofrimento físico ou psicológico a este. E o princípio que diz respeito ao amparo jurídico dos animais a fim de que seja garantida a tutela jurídica e seus direitos assegurados. Outro princípio seria o da obrigatoriedade de intervenção do Poder Público, devendo este gerir ou administrar o meio ambiente. Há, ainda, o princípio da proporcionalidade, que defende a adequação dos meios necessários para proteger o meio ambiente.

No que tange ao termo responsabilidade, segundo o minidicionário de Silveira Bueno (2007, p. 676), significa, a obrigação de responder pelos seus atos ou pelos de outrem. Portanto, serve para indicar a circunstância que alguém deverá arcar com as consequências de seus atos, comissivos ou omissivos, que gerou algum dano.

Em relação ao Estado, sua responsabilidade é apontada no artigo $37, \S 6^{\circ}$ da Constituição da República Federativa de 1988 que esclarece que as pessoas jurídicas de direito público e de direito privado que prestam serviços públicos respondem pelos danos causados a terceiros.

Ainda o art. 225, $\S 3^{\circ}$ da Constituição dispõe que "as condutas e atividades consideradas lesivas ao meio ambiente sujeitarão os infratores, pessoas físicas ou jurídicas, a sanções penais e administrativas, independentemente da obrigação de reparar os danos causados". O texto constitucional ao determinar essa tríplice punição demonstra que o meio ambiente é protegido civilmente, administrativamente e penalmente, protegendo interesses distintos e submetidas a regimes jurídicos diferentes. 
Desta forma, verifica-se que o município sendo uma pessoa jurídica de direito público interno, é responsável por todas as condutas, inclusive ambientais. Este ente federativo possui autonomia financeira, política e administrativa, sendo capaz de se auto-organizar e elaborar suas Leis Orgânicas desde que respeite a Constituição Federal e Estadual. Ainda como dispõe o artigo 18 da CF a União, os Estados, o Distrito Federal e os Municípios são autônomos e fazem parte da organização políticoadministrativa da República Federativa do Brasil.

Sendo assim, o município é responsável pelas condutas praticadas pelos seus representantes, e em casos de animais abandonados nas ruas, deve o município guardá-los e protegê-los, pois se não, pode sofrer as sanções cabíveis.

Entende-se que tanto a Constituição Federal quanto a Lei de Política Nacional do Meio Ambiente (Lei n. 6.938/1981) e com fundamento na teoria do risco integral, que pressupõe uma responsabilidade ampla, a responsabilidade civil do Estado pelo dano ambiental é extracontratual, solidária e objetiva.

Para Cavalieri (2014) em seu sentido etimológico e também no sentido jurídico, a responsabilidade civil está atrelada à ideia de contraprestação, encargo e obrigação, ligada a noção de desvio de conduta. Entretanto é importante distinguir a obrigação da responsabilidade. A obrigação é sempre um dever jurídico originário; responsabilidade é um dever jurídico sucessivo consequente à violação do primeiro. Significa dizer que, a responsabilidade do município em casos de abandonos de animais é objetiva, devendo apenas verificar se há nexo causal entre o dano e a conduta, e tem função preventiva e reparatória.

Nas situações de abandono de animais a omissão do ente federativo, se configura quando o mesmo tendo o dever de agir em prol dos animais, se omite desta responsabilidade. O município tem a prerrogativa de elaborar suas próprias leis, Leis Orgânicas, conforme previsto no art. 29, caput da CF, sendo capaz de se auto-organizar para disciplinar sobre as problemáticas locais e buscar atender os pleitos demandados.

Dentre as hipóteses de dano ambiental pela omissão tem-se o caso que a norma prevê a atuação do município, porém o mesmo não age para prevenir o dano, caracteriza, assim, a responsabilidade por ato ilícito omissivo próprio, e quando a norma aponta o resultado danoso, mas o município não age para prevenir o dano restando configurada a responsabilidade por ato ilícito omissivo impróprio.

Ainda é de responsabilidade do poder público desenvolver campanhas educativas a fim de garantir que a compra ou adoção de animais não seja por impulso, cadastro público dos animais com informações individuais de cada animal (espécie, tamanho, nome, entre outras informações que forem necessárias para identificação), programa de esterilização abrangente estipulando baixo preço ou até mesmo, quando puder, de forma gratuita para as pessoas de baixa renda, havendo a integração das três esferas do poder Público e o que é estabelecido pelo SISNAMA (Sistema Nacional de Meio Ambiente). É nesse sentido que se configura a responsabilidade civil do Município perante os animais domésticos abandonados, cães e gatos, visto que estes estabelecem vínculo de dependência com o ser humano, o que importa para sua sobrevivência.

A responsabilidade penal no município é uma consequência advinda da omissão ou comissão do ente, sendo tipificada como crime ou contravenção penal. Esta responsabilização tem como penalidade algumas sanções penais dispostas da Constituição Federal e na lei n 9.605/98.

A responsabilidade administrativa, também tutelado pela Constituição Federal e a lei n 9.605/98, tem por objetivo defender e preservar o meio ambiente para as futuras gerações, sendo configurada quando o ente federativo infringir as regras da Administração Pública e, portanto, será aplicada sanções administrativas, elencadas no art. 72 da Lei de Crimes Ambientais. Conforme o art. 70 da referida lei, a infração administrativa ambiental é observada quando há uma ação ou omissão que viole o uso, gozo, proteção e o meio ambiente.

Em relação ao exercício do direito dos animais, o artigo 127, da CF de 1988, esclarece que "O Ministério Público é instituição permanente, essencial à função jurisdicional do Estado, incumbindo-lhe a defesa da ordem jurídica, do regime democrático e dos interesses sociais e individuais indisponíveis.". Desta forma, o Ministério Público passa a ser a instituição apropriada para tutelar os interesses sociais, 
difusos e coletivos.

O Ministério Público, através da representação, tem a competência de agir criminalmente, civilmente e administrativamente, quando as normas ambientais forem descumpridas, a fim de proteger 0 meio ambiente, o mantendo ecologicamente equilibrado, e, portanto, os animais serão sujeitos de direito, dotados de personalidade jurídica, podendo ter seu direito atendido quando houver violação. Desde o Decreto n. 24.645 de 1934, em seu artigo art. 2, $\S 3^{\circ}$, todos os animais passariam a ser tutelados pelo Estado sendo assistidos juridicamente pelos representantes do Ministério Público.

Não menos importante, deve-se destacar a responsabilidade dos tutores que devem adotar a prática da guarda responsável, planejando quantos animais podem cuidar e o que deve ser feito para que estes sejam saudáveis. Por outro lado, é válido ressaltar que o abandono de animais e maus tratos constitui crime ambiental de acordo com artigo 225 CF, Lei de Crimes Ambientais (n 9.605/98) e o art. 164 do Código Penal Brasileiro.

Desse modo, a responsabilidade objetiva do município pelos animais abandonados, pelo fato de existir o nexo de causalidade entre o fato gerador e dano, pois como já discutido, o município deve propor e executar medidas que visem prevenir o abandono de animais.

\section{ENTENDIMENTO JURISPRUDENCIAL}

O município tem responsabilidade pelos animais abandonados pois tem o dever constitucional de proteger e zelar pelo meio ambiente. A de se falar ainda que a superpopulação desses seres viventes pode corroborar com a proliferação de zoonoses, e desta forma atinge outros direitos, inclusive os direitos sociais. Sobre esse prisma os tribunais têm adotado e decidido sobre a responsabilização do município, como forma de obrigar que este cumpra sua obrigação.

Vale aqui citar o julgado do Tribunal de Justiça do Rio Grande do Sul, apelação cível, $\mathrm{n}^{\circ}$ 70070773122, da Vigésima Primeira Câmara Cível, do Relator Marco Aurélio Heinz, julgado em 14/09/2016, que aponta a competência do município em manter a guarda dos animais domésticos abandonados através do recolhimento e abrigo. Nesse sentido, o Supremo Tribunal Federal (STF), determina que o Poder Judiciário pode implantar políticas públicas por se tratar de garantia fundamental. Citando o artigo 13, I da CF/88 para afirmar que é de competência do município a guarda de animais domésticos abandonados, o que confirma o que já foi exposto neste artigo.

Acrescenta-se a apelação cível, n 70066150749 , da Terceira Câmara Cível, do Tribunal de Justiça do RS, da relatora Matilde Chabar Maia, julgado em 28/04/2016, cita o art. 225 da CF/88, já mencionado neste trabalho, e no mesmo sentido, aponta para o compromisso do município em efetuar a esterilização/castração e vacinação dos animais abandonados quando há situação de risco à saúde pública, pois constitui responsabilidade do município adotar ações que visem a obtenção de um meio ambiente equilibrado, protegendo à fauna. Desta forma, resta comprovado a competência e a responsabilização do município frente aos animais domésticos abandonados nas ruas, quando este se omite em prevenir o abandono ou até não proteger os animais nessa situação de vulnerabilidade.

\section{RELATOS DE EXPERIÊNCIAS EXITOSAS NO BRASIL}

Os entes públicos podem ser obrigados a contribuir com as ONG's protetoras de animais abandonados, conscientizar a população, promover campanhas de castração e vacinação. Desta forma, essas entidades tem a finalidade de fornecer um lar temporário aos animais necessitados até que estes sejam adotados. Não ocorrendo à adoção, o que era para ser um lar temporário passar a ser permanente. E em muitos casos, essas ONG's carecem de estrutura e incentivos financeiros comprometendo a saúde dos animais e impossibilitando de ajudar outros animais que necessitam.

No Acre, a Vara de Execuções Penais destinou quase 19 mil reais para que um pet shop pudesse comprar ração e realizar castração e cirurgia, visto que é costume desta Vara atender diversos projetos 
de interesse social que tenham relevância e amplitude social. Outro exemplo que pode ser citado é o da cidade de Esteio (RS), situada na Região de Porto Alegre, que fundou um projeto denominado Projeto Socioambiental com o objetivo de conscientizar a população sobre a importância de proteger e cuidar dos animais e do meio ambiente, sendo ainda desenvolvidas campanhas de castração e vacinação, e com o apoio do Grupo dos Amigos e Tratadores de Animais (GATA), foi realizado a colocação de microchip e cirurgias.

Em Camaquã (RS), a secretaria do Meio Ambiente assinou com a ARCA - Associação Protetora de Animais de Rua de Camaquã, um convênio com o intuito de repassar $\mathrm{R} \$ 2.000$ por mês para assistência e castração de cães e gatos recolhidos pela ARCA, com o intuito de reduzir a população de animais domésticos de forma humanitária através de castração e desenvolvendo um programa para adoção e guarda responsável, evitando a proliferação e o abandono desses animais.

Pode-se observar a atuação do Ministério Público por meio de ações civis públicas e das associações protetoras dos animais que têm cobrado dos entes públicos a responsabilidade que possuem. Como por exemplo o julgado da primeira turma do Tribunal de Justiça do RS, do relator Henrique Osvaldo Poeta Roenick, julgado em 26/03/2008, apelação Cível $n^{\circ} 70023027758$, onde a associação protetora de animais, através de uma ação civil pública, aponta a responsabilidade do município de Camaquã pelo recolhimento, abrigo e tratamento de animais abandonados.

No município de Ilhabela (SP), o Juiz determinou que a prefeitura fornecesse mensalmente $750 \mathrm{Kg}$ de ração para o abrigo de cães e gatos por se tratar de uma obra de interesse público, que retira os animais das ruas do referido município e ainda busca dar dignidade a estes seres abandonados tanto pelos donos quanto pelo Poder Público.

Em São Cristóvão (RJ), o Instituto de Zoonoses e Medicina Veterinária Jorge Vaitsman, ligado à prefeitura, inaugurou uma ala para atendimento de gatos, sendo equipada com consultórios, sala de espera e sala para aplicação de medicamentos. Além de oferecer outros tipos de assistência e tratamento para algumas doenças como sarnas, micoses e diversos tipos de zoonoses.

Além desses entendimentos jurisprudenciais, existem outras inovações nessa área, como é o caso da criação de delegacias especializadas para proteção animal e delegacia eletrônica de proteção animal (DEPA) em São Paulo.

Com a aprovação da Lei 16.303/16 foi instituída a DEPA, sendo a primeira do gênero no país. Com isso o cidadão pode fazer a denúncia proporcionando maior agilidade nas averiguações de crimes contra animais. O reflexo disso é que no último ano, vários projetos de DEPA já foram protocolados em diversos estados, como é o caso do Rio Grande do Sul, Rio de Janeiro, Rondônia, Minas, Paraíba, Bahia, entre outros.

Em São Paulo aconteceu o caso da chipanzé Cecília, moradora do zoológico de Mendonza, na Argentina, que atualmente encontra-se no Santuário de Grandes Primatas, em Sorocaba (SP), devido a impetração de um Habeas Corpus, concedido pela Juíza Maria Alejandra Maurício afirmando que "O chipanzé não é uma coisa, não é um objeto do qual pode se dispor, como se dispõe de um automóvel."

$\mathrm{Na}$ cidade de Salvador (BA), em 2005, o Promotor de Justiça, Heron Gordilho, também impetrou um Habeas Corpus, $n^{\circ}$ 833085-3/2005, em favor de uma chipanzé, porém a mesma faleceu antes de ter seu pedido julgado, por isso, é retrocesso considerar que os animais não humanos não são sujeitos de direitos.

Na cidade de Cruz das Almas (Ba), funciona um canil, mantido pela prefeitura desde 2008, e dados de 2017 revelam que existem 48 cães, e o resgate dos animais abandonados é realizado por uma equipe capacitada para este tipo de situação. Neste local existe um funcionário e há convênio com o Hospital Universitário de Medicina Veterinária da Universidade Federal do Recôncavo Baiano (UFRB) onde são feitas consultas e outros procedimentos necessários. Para o ano de 2018 está prevista uma campanha de castração e anualmente há a campanha de vacinação antirrábica.

Ainda na Bahia, os municípios de Serrinha, Barrocas, Biritinga e Teofilândia firmaram Termos de Compromisso de Ajustamento Preliminar com o Ministério Público Estadual afim de implementar ações com o intuito de efetivar as políticas públicas de controle da população de animais domésticos em 
situação de vulnerabilidade, tendo o prazo de 90 (noventa) dias para apresentar ao MP um projeto que solucione os problemas atuais. Este termo, foi proposto pela promotora de Justiça Letícia Baird, que prevê a prestação de serviço médico-veterinário para os animais abandonados ou tutelados por pessoas de baixa renda.

As ações vão desde a implantação de comedouros e bebedouros para os animais abandonados a capacitação agentes públicos, realização de campanhas educativas para a população, entre outras medidas que visem a proteção e defesa dos direitos dos animais. Ainda como fruto desta atuação da Promotoria ocorreu a capacitação dos guardas municipais, agentes comunitários de saúde e agentes de endemias dos quatro municípios, com o intuito de habilitar estes agentes a identificar casos de maus tratos contra animais e técnicas de regaste. Segundo a Promotora de Justiça Letícia Baird, autora do TAC:

"Refletir com a sociedade e gestores públicos sobre estratégias e responsabilidades para a efetivação dos direitos de animais vulneráveis, a exemplo de cães e gatos abandonados, mais que traduzir importante questão de justiça social é, sobretudo, edificar alicerces sustentáveis e éticos para a presente e futuras gerações".

Nas cidades do interior, principalmente, com as mudanças de gestão, muito do que foi conquistado acaba se perdendo por que o novo gestor tem outras prioridades que tragam mais impactos aos olhos da sociedade e por vezes acabam esquecendo destes seres que só querem um pouco de comida e cuidado. O assunto relativo a implementação de políticas públicas de proteção e defesa dos animais tem sido alvo de discussões, porém, o que se observa é que as ações não são postas em prática.

Desse modo, já existem decisões que obrigam o município e o Estado a desempenhar funções que acolham e protejam cães e gatos, através de criação de abrigos, vacinação, castração, doação responsável, entre outros. É nesse sentido que o município de Santo Antonio de Jesus deve atuar desenvolvendo ações que visem cumprir a lei, beneficiando a população, os animais abandonados e os já recolhidos pela única ONG existente na cidade.

\section{A REALIDADE DA PROTEÇÃO E DEFESA DOS ANIMAIS URBANOS DE SANTO ANTONIO DE JESUS-BA}

Em 2012 foi instaurado um inquérito civil n 037/2012, que teve representação das responsáveis pela ONG Amo Animais, com o intuito de solucionar a falta de um centro de zoonoses e de um canil e gatil no município de Santo Antonio de Jesus-Ba. Em 2014, o Ministério Público (MP) requisitou ao prefeito a criação urgente do centro de zoonoses além do abrigo para os cães e gatos, de modo a contribuir com a ONG, todavia, não houve resposta nem a realização de qualquer ação e, por isso, ingressou com uma ação civil pública, $\mathrm{n}^{\circ}$ 0303144-95.2014.805.0229.

Durante esta ação também foram ouvidas a Diretora da Vigilância à saúde e o Coordenador da Vigilância Sanitária de Santo Antonio de Jesus, e ambos, coadunaram com a necessidade da criação de um centro de zoonoses e que alguns vezes esses setores buscam a ajuda do Corpo de Bombeiro e da própria ONG, que não recebe nenhuma ajuda financeira para isto. Ressalta-se que a Lei Orgânica do Município de Santo Antonio de Jesus, promulgada em 05/04/1990, em seus artigos 16 incisos XVIII e XIX aduz a competência do município em dispor de registro, vacinação e captura dos animais além do depósito, venda ou doação de animais. E art. 17 inciso VII da referida lei dispõe sobre a preservação das florestas, fauna e flora em conjunto com a União e o Estado.

Restando configurado a omissão do poder público, visto que é inquestionável a obrigação do município de Santo Antonio de Jesus perante os animais abandonados, e além do mais, deve viabilizar campanhas de castração para haver controle de natalidade dos mesmos. A situação é tão notória que os blogs locais, Blog do Valente (2011), Voz da Bahia (2012) e Tribuna do Recôncavo (2016) confirmam o problema através de reportagens que alertam sobre o ataque de cães aos transientes e a presença de animais doentes que acabaram transmitindo algumas doenças de pele para as pessoas do bairro, entretanto, o poder público continua sem dar uma resposta para a sociedade. 
São relatos como estes que confirmam a grande presença de animais abandonados nas ruas. Vale ressaltar, que duas dessas reportagens foram de 2011 e 2012 o que subtende-se que esses animais se reproduziram ao longo desses anos, outros tantos foram abandonados e essa quantidades de animais abandonados aumentou gradativamente. É de extrema relevância destacar a atuação do Instituto de Proteção dos Animais Domésticos e Domesticados do Recôncavo Baiano- AMO ANIMAIS, que é uma ONG (Organização não Governamental) que atua com o objetivo de resgatar animais domésticos e domesticados das ruas de Santo Antônio de Jesus, com o intuito de tratá-los e dispor para doação.

A ONG AMO ANIMAIS em acordo com art. $3^{\circ}$ da Lei 9.790/99 tem como finalidade promover a educação da população, promoção da saúde coletiva ajudando os órgãos públicos responsáveis a coletar e tratar animais com potencial risco de transmissão de doenças, fiscalizar o cumprimento dos direitos dos animais estabelecidos nas legislações, averiguar ato de crueldade, colaborar com as instituições públicas e privadas e promover o voluntariado, com o intuito de modificar a realidade social e ambiental mundial. Conforme o estatuto social a instituição tem 7 (sete) anos de registrada, e atualmente abriga 137 cães, vem sendo mantida através de doações, bazar, rifas e valores referentes a penas pecuniárias enviadas pelo Ministério Público.

Geralmente os animais são recolhidos pelos voluntários da ONG quando podem e quando possuem meios para o resgate, e a depender da situação, são encaminhados para o veterinário ou são tratados na própria ONG pelos voluntários. Esses animais recolhidos são contemplados com as campanhas de vacinação do município, porém, não tem acompanhamento veterinário regularmente por falta de verba. Esporadicamente algum veterinário da cidade comparece a ONG para examinar alguns animais, mas, infelizmente, não dão seguimento a estes acompanhamentos.

Dados de setembro de 2017 apontam que a ONG possui um quadro de 4 (quatro) funcionários, sendo (1) um de 44 (quarenta e quatro) horas semanais, outro de 22 (vinte e duas) horas semanais e mais 2 (dois) diaristas que reversam os domingos e feriados. E a ajuda dos voluntários para banho, higienização do abrigo, passeio com os cães que ficam em baias menores por algum motivo de doença.

Em, 17 de dezembro de 2015, termo aditivo n 927/2015, foi firmado um convênio $n^{\circ}$ 004/2015 entre o município de Santo Antonio de Jesus e a ONG AMO ANIMAIS, com o objetivo de assessorar a ONG em relação aos serviços de recolhimento, alimentação e tratamento de animais domésticos e domesticados abandonados nas ruas do município, sendo que seria repassado o valor de $\mathrm{R} \$ 7.000,00$ (sete mil reais) mensais durante 12 meses, período que compreende entre 01/01/2016 a 31/12/2016, destas só 8 (oito) parcelas foram repassadas.

No dia 25 de setembro de 2017 o projeto que autoriza o repasse de verbas para custeio da ONG AMO ANIMAIS, foi aprovado pela Câmara de Vereadores, porém até o momento não houve nenhum repasse, sendo alegado que há pendência em relação à alguns documentos da ONG, e desta forma, os animais continuam passando por necessidades. Além disso registra-se que não existe outra ONG que resgate animais abandonados, porém sabe-se da existência de pessoas, individuais ou em grupos, que dão abrigo a estes em suas casas até que consiga doá-los.

Dados da Vigilância Sanitária Municipal de Santo Antonio de Jesus demonstram que, atualmente, não está sendo desenvolvida ações de conscientização da população em relação ao abandono, nem de castração e nem resgate de animais domésticos em situações de risco. Esse órgão atua quando há necessidade de averiguar alguma situação e encaminha relatório para o Ministério Público, e este irá agir na situação.

Em relação aos animais de grande porte, como por exemplo cavalo, a vigilância sanitária, atuava quando havia necessidade, e por isso o município contratou um vaqueiro, mas atualmente essa responsabilidade foi passada para a Secretaria de Agricultura. Outro fator importante é que a verba destinada para o CCZ (Centro de Controle de Zoonoses) é somente para a implantação, devendo o munícipio arcar com a manutenção desse centro, o que se torna muito dispendioso, porém é de extrema necessidade, já que existem muitos animais abandonados e a população de Santo Antonio de Jesus já ultrapassa 100 mil habitantes.

Enfim, já que é de interesse e responsabilidade do município a guarda e proteção dos animais em 
situação de risco, estes devem colaborar com a ONG e resolver as pendências já que a entidade não possui recurso financeiro para arcar com todos os documentos necessários.

\section{CONSIDERAÇÕES FINAIS}

Após a análise de doutrinas e jurisprudências é visível que o município é o responsável por acolher e cuidar dos animais domésticos abandonados, visto que este ente federativo é autônomo para criar suas leis de acordo com as necessidades locais. A responsabilidade que norteia o Direito Ambiental é objetiva, e tem como base a teoria do risco integral, e para isso deve-se observar se há nexo de causalidade entre o dano e o fato obrigando o município a indenizar qualquer dano que decorra de sua comissão ou omissão.

Além da responsabilidade civil, o município pode responder penalmente e/ou administrativamente, sendo que na primeira o responsabilizado será a pessoa jurídica, e na segunda, aplicada pelo Poder Público através do poder de polícia. Desta forma, o município poderá sofrer sanções nessas esferas se não agir conforme o estabelecido, ou seja, se não cumprir com seu dever de guarda e proteção.

O que se observa no dia-a-dia é que o poder público, de modo geral, carece de políticas que ajudem amenizar o problema, sendo necessário instituir políticas públicas participativas que visem conscientizar a população acerca do abandono de animais, edição de lei municipal para regulamentar esse assunto, criação de abrigo público para retirar os animais da zona de risco que se encontram quando abandonados, manter comedouros e bebedouros espalhados na cidade para que os animais em situações de risco possam se alimentar, firmar convênios com hospitais veterinários ou até mesmo com pet shop para que os animais sejam atendidos, promover ações de controle populacional através da castração além de ações que tenham como objetivo a educação ambiental, seja nas escolas, nos meios de comunicação local ou nos postos de saúde.

Assunto este disciplinado na Constituição Federal que tem como reflexo construir um saber ambiental voltado para os valores éticos, no convívio com o outro e com o meio ambiente, considerando que a sociedade é responsável pelos problemas ambientais. Este tema deve ser discutido e implementado desde o ensino básico, com a ajuda da família, para que as crianças criem uma consciência crítica e responsável acerca do meio ambiente e os conflitos socioambientais.

Após o acolhimento e os cuidados necessários os animais devem ser disponibilizados para a adoção responsável, contribuindo para a diminuição de animais nas ruas e nas ONGs, oferendo espaço para que outros animais sejam ajudados. Devendo destacar ainda que a população também deve colaborar não abandonando os animais, atitude esta considerada como crime, prestando serviços comunitários as ONGs ou abrigos públicos, fiscalizar e cobrar do poder público ações no sentido de proteger os animais para que existam cada vez menos animais em situações de risco.

Esta pesquisa teve como objetivo norteador esclarecer a responsabilidade do município em relação aos animais domésticos abandonados na cidade de Santo Antonio de Jesus/Ba e identificar quais ações o município tem desenvolvido para proteger estes animais abandonados. Portanto, através desse estudo pode-se perceber a carência de ações desenvolvidas no município para amparar os animais abandonados, visto que a ação civil pública instaurada em 2014 pelo MP da referida cidade encontra-se sem nenhuma movimentação. O convênio firmado, em 2015, entre o município e a ONG AmoAnimais foi descumprido, só havendo o repasse de poucas parcelas. E o último convênio firmado em setembro de 2017, ainda não está sendo cumprido.

Enquanto isso, os animais continuam tendo seus direitos, previstos por lei, violados pois o município não age de acordo com seus deveres, visto que tem a responsabilidade de proteger e zelar pelos animais abandonados, podendo ser obrigados, por decisões judiciais a cumprir o seu papel. 


\section{REFERÊNCIAS}

A Declaração de Cambridge sobre a consciência em animais humanos e não-humanos. Pet Imagem. Disponível em: http://www.petimagem.com.br/A-Declaracao-de-Cambridge-sobre-a-consciencia-em-animais-humanos-enao-humanos.aspx. Acesso em: 23 nov. 2017

ALA para atendimento exclusivo de gatos é inaugurada em instituto do Rio. ANDA. [S.I; s.n], 2017. Disponível em: <https://www.anda.jor.br/2017/10/ala-para-atendimento-exclusivo-de-gatos-e-inaugurada-em-instituto-do-rio/>. Acesso em: 12 set. 2017.

ALMEIDA, Jeovaldo da Silva. Proteção aos animais. Âmbito Jurídico. [S.I; s.n]. 2013. Disponível em: $<\mathrm{http}: / /$ www.ambito-juridico.com.br/site/?n_link=revista_artigos_leitura\&artigo_id=13011>. Acesso em: 10 nov. 2017

ALVES, Hélio. Homem foi atacado por cachorro enquanto pilotava moto em Santo Antônio de Jesus. Tribuna do Recôncavo. Santo Antonio de Jesus. 2016. Destaque. Disponível em: <http://tribunadoreconcavo.com/homem-eatacado-por-cachorro-enquanto-pilotava-moto-em-santo-antonio-de-jesus/>. Acesso em: 07 nov. 2017.

A N I M A I S D o m é sticos. [ S.I; s.n]. Dis pon ível e m : <https://www.suapesquisa.com/mundoanimal/animais_domesticos.htm>.Acesso em: 17 out. 2017.

ANIMAIS resgatados de maus tratos. [S.I; S.n], 2017 . Disponível em: <https://www.vakinha.com.br/vaquinha/animais-resgatados-de-maus-tratos>. Acesso em: 10 set. 2017.

ANTUNES, Paulo de Bessa. Direito Ambiental. $17^{\circ}$ ed. São Paulo: atlas S.A, 2015.

ARAÚJO, Thaís Montenegro. A responsabilidade do munícipio na proteção e guarda dos animais abandonados. TCC. 2016 Disponível em: <http://dspace.bc.uepb.edu.br/jspui/handle/123456789/11368>. Acesso em: 19 jun. 2017.

BRASIL, CÂMARA DOS DEPUTADOS. Comissão considera animais não humanos como sujeitos de direitos. Meio Ambiente. Brasília: [s.n], 2015. Disponível em: <http://www2.camara.leg.br/camaranoticias/noticias/MEIOAMBIENTE/498051-COMISSAO-CONSIDERA-ANIMAIS-NAO-HUMANOS-COMO-SUJEITOS-DEDIREITOS.html>. Acesso em: 25 set. 2017.

BRASIL, DECRETO № 24.645, de 10 de julho de 1934. Publicado no diário oficial de 13 de julho de 1948. Disponível em:<http://funed.mg.gov.br/wp-content/uploads/2010/05/Decreto-lei-24645-34-maus-tratos-animais.pdf>. Acesso em: 12 set. 2017.

BRASIL. Lei no 13.426, de 30 de março de 2017. Publicado no diário oficial em 31 de março 2017. Brasília: [s.n.], 2017. Disponível em: <http://www.planalto.gov.br/ccivil_03/_ato2015-2018/2017/lei/L13426.htm>. Acesso em: 01 nov. 2017.

BRASIL. Constituição da República Federativa do Brasil: promulgada em 5 de outubro de 1988. Disponível em:<http://www.planalto.gov.br/ccivil_03/Constituicao/Constituicao.htm>. Acesso em: 28 fev. 2019.

BRASIL. Lei $n^{\circ} 10.406$, de 10 de janeiro de 2002. Código Civil Brasileiro. Disponível em:< http://www.planalto.gov.br/ccivil_03/LEIS/2002/L10406.htm>. Acesso em: 28 fev. 2019.

BRASIL. Lei no 9.605, de 12 de fevereiro de 1998. Dispõe sobre as sanções penais e administrativas derivadas de condutas e atividades lesivas ao meio ambiente, e dá outras providências. Publicado no diário oficial em 12 de fevereiro 1998. Brasília: [s.n.], 2017. Disponível em: <http:// http://www.planalto.gov.br/ccivil_03/LEIS/L9605.htm>. Acesso em: 28 fev. 2019.

BRASIL. Lei no 9.605, de 12 de fevereiro de 1998. Dispõe sobre as sanções penais e administrativas derivadas de condutas e atividades lesivas ao meio ambiente, e dá outras providências. Publicado no diário oficial em 12 de fevereiro 1998. Brasília: [s.n.], 2017. Disponível em: <http:// http://www.planalto.gov.br/ccivil_03/LEIS/L9605.htm>. Acesso em: 28 fev. 2019.

BRASIL. MINISTERIO PÚBLICO DO ESTADO DA BAHIA. Acordo com Ministério Público resulta em semana do Meio Ambiente em Serrinha. Notícia. Meio Ambiente. Salvador: [s.n.], 2017. Disponível em: <http://www.mp.ba.gov.br/noticia/38777>. Acesso em: 08 nov. 2017. 
BRASIL. MINISTERIO PÚBLICO DO ESTADO DA BAHIA. MP promove ações para discutir políticas públicas para atendimento a animais domésticos em situação de vulnerabilidade. Notícia. Meio Ambiente. Salvador: [s.n.], 2017. Disponível em: <http://www.mp.ba.gov.br/noticia/38656>. Acesso em: Acesso em: 08 nov. 2017.

BRASIL. MINISTERIO PÚBLICO DO ESTADO DA BAHIA. Município de Biritinga promove evento para discutir defesa dos direitos dos animais após acordo com MP. Notícia. Meio Ambiente. Salvador: [s.n.], 2017. Disponível em: <http://www.mp.ba.gov.br/noticia/40052>. Acesso em: 08 nov. 2017.

BRASILEIROS têm 52 milhões de cães e 22 milhões de gatos, aponta IBGE. G1. Natureza. São Paulo: [s.n], 2015. Disponível em: <http://g1.globo.com/natureza/noticia/2015/06/brasileiros-tem-52-milhoes-de-caes-e-22-milhoesde-gatos-aponta-ibge.html>. Acesso em: 09 jul. 2017.

CAMAQUÃ, Prefeitura. Prefeitura assina convênio com a ARCA. Camaquã: [s.n], 2015. Notícia. Disponível em: <http://www.camaqua.rs.gov.br/noticias/657/prefeitura-assina-convenio-com-a-arca.html >. Acesso em 23 de maio de 2017. Acesso em: 17 jul. 2017.

CÂMARA aprova mudança da natureza jurídica dos animais, de coisas para bens móveis. Avicultura. Meio Ambiente. 2017. Disponível em: <https://www.aviculturaindustrial.com.br/imprensa/camara-aprova-mudanca-danatureza-juridica-dos-animais-de-coisas-para-bens/20170829-122030-a598>. Acesso em: 25 set. 2017.

CAVALIERI, Sergio Filho. Programa de responsabilidade civil. 11 ed. rev. e amp. São Paulo: Atlas, 2014. 14p.

CONCEITO de Animais Domésticos. [S.I; s.n], 2012 Disponível em: <http://www.meioambienteecidadania.com.br/2012/11/conceito-de-animais-domesticos.html>. Acesso em: 16 jul. 2017.

CONCEITO de Animais Domésticos. [S.I; s.n]. Disponível em: <http://queconceito.com.br/animais-domesticos>. Acesso em: 17 out. 2017.

CONCEITO. [S.I; s.n]. Disponível em: <https://conceito.de/animais-domesticos>. Acesso em: 17 out. 2017.

DECLARAÇÃO de Cambridge sobre consciência animal. Disponível em: <http://www.labea.ufpr.br/portal/wpcontent/uploads/2014/05/Declara\%C3\%A7\%C3\%A3o-de-Cambridge-sobre-Consci\%C3\%AAncia-Animal.pdf> . Acesso em: 23 nov. 2017.

DEPA: Delegacia Eletrônica de Proteção Animal completa um ano. ANDA. [S.I; s.n], 2017. Disponível em: <https://www.anda.jor.br/2017/09/depa-delegacia-eletronica-de-protecao-animal-completa-um-ano/>. Acesso em: 12 set. 2017.

FARIAS, C. C; ROSENVALD, N. Curso de Direito Civil: Reais. $9^{\circ}$ ed. rev. e atual. Salvador: JusPodivm, 2013.

FAUTH, Juliana de Andrade. A natureza jurídica dos animais: rompendo com a tradição antropocêntrica do Direito Civil. Conteúdo Jurídico. 2015. Disponível em: <http://www.conteudojuridico.com.br/artigo,a-natureza-juridica-dosanimais-rompendo-com-a-tradicao-antropocentrica-do-direito-civil,55893.html>. Acesso em: 10 out. 2017.

FILHO. Arnaldo de Souza Menezes. POLÍTICAS PÚBLICAS DE PROTEÇÃO AOS ANIMAIS: formulação e implementação. Disponível em: <http://www.joinpp.ufma.br/jornadas/joinpp2013/JornadaEixo2013/anais-eixo3estadolutassociaisepoliticaspublicas/politicaspublicasdeprotecaoaosanimais-formulacaoeimplementacao.pdf>. Acesso em: 15 de maio 2017.

FROEHLICH, Graciela. Entre índices e sentimentos: notas sobre a ciência do bem-estar animal. Disponível em: http://www.revistaflorestan.ufscar.br/index.php/Florestan/article/download/136/pdf_67. Acesso em: 23 nov. 2017

JUIZ determina que Prefeitura forneça $750 \mathrm{~kg}$ de ração diária para abrigo mantido por ONG. Associação Viva Bicho. [S.I; s.n], 2016. Disponível em: <http://associacaovivabicho.org.br/juiz-determina-que-prefeitura-forneca-750-kgde-racao-diaria-para-abrigo-mantido-por-ong/> . Acesso em 23 de maio de 2017.

Justiça destina quase R\$ 19 mil para castração de animais em Cruzeiro do Sul (AC). ANDA. [S.I; s.n], 2017. Disponível em: <https://www.anda.jor.br/2017/10/justica-destina-quase-19-mil-para-castracao-cruzeiro-do-sulac/>. Acesso em: 12 nov. 2017. 
KURATOMI, Vivian Akemi. Os animais como sujeitos de direitos no ordenamento jurídico brasileiro. Brasília. [s.n.] Monografia. Disponível em: <http://repositorio.uniceub.br/bitstream/123456789/326/3/20659048.pdf>. Acesso em: 18 jun. 2017.

MURARO, C. C; ALVES, D. N. Maus tratos de cães e gatos em ambiente urbano, defesa e proteção aos animais. Â m b i to Ju ríd i co. [S.I; s.n]. A m biental. D is ponível e m: <http://www.ambitojuridico.com.br/site/?n_link=revista_artigos_leitura\&artigo_id=14571>. Acesso em: 09 out. 2017.

NAIME, ROBERTO. Fauna. EcoDebate. [S.I; s.n], 2011 . Disponível em: <https://www.ecodebate.com.br/2011/05/05/fauna-artigo-de-roberto-naime/>. Acesso em: 09 out. 2017.

OLIVEIRA, Letícia. Cadela ataca idosa em Santo Antônio de Jesus. Santo Antonio de Jesus. 2012. Voz da Bahia. Cidades. Disponível em: <http://www.vozdabahia.com.br/index/blog/?cat=532\&start=1355208522>. Acesso em: 07 nov. 2017.

PANDOLFO, Aline. A responsabilidade civil do munícipio frente ao abandono de animais. Monografia. 2010. Disponível em: <http://siaibib01.univali.br/pdf/aline\%20pandolfo.pdf>. Acesso em: 19 jun. 2017.

PONTES, Bianca. Lei $n^{\circ}$ 11.101/11: Análise das políticas públicas para animais domésticos e domesticados no município de Porto Alegre. On-line. Disponível e m: <https://portalseer.ufba.br/index.php/RBDA/article/viewFile/8419/6033>. Acesso em: 15 maio 2017.

REIS, Marta F. Animais já têm estatuto jurídico. E são seres vivos dotados de sensibilidade. Sol. Sociedade. [s.n], 2017. Disponível em: <https://sol.sapo.pt/artigo/551832/animais-ja-t-m-estatuto-juridico-e-sao-seres-vivosdotados-de-sensibilidade->. Acesso em: 29 agosto 2017.

RESPONSABILIDADE. In: BUENO, Francisco da Silveira. Minidicionário da língua portuguesa. 2 ed. São Paulo: FTD, 2007. pg. 676.

SILVA, L; MASSUQUETTI, A. POLÍTICAS PÚBLICAS DE PROTEÇÃO E DEFESA DOS ANIMAIS URBANOS: O CASO DE SAPUCAIA DO SUL (RS). Disponível em: <http://www.fee.rs.gov.br/wpcontent/uploads/2014/05/201405267eeg-mesa24-politicaspublicasprotecaodefesaanimaispublicas.pdf>. Acesso em: 15 maio 2017.

SILVA, Rodrigo Daniel. "Garantir os direitos dos animais é uma questão moral antes de ser jurídica". Consultor Jurídico. [S.I; s.n], 2017. Disponível em: <https://www.conjur.com.br/2017-jan-07/entrevista-heron-gordilhopromotor-mp-ba>. Acesso em: 07 de agosto 2017.

TARTUCE, Flávio. Direito Civil: Lei de Introdução e Parte Geral. $13^{\circ}$ ed. rev. e atual. ampl. Rio de Janeiro: Forense, 2017.

UNESCO. DECLARAÇÃO UNIVERSAL DOS DIREITOS DOS ANIMAIS. Bruxelas: [s.n], 1978. Disponível em: <http://portal.cfmv.gov.br/portal/uploads/direitos.pdf>. Acesso em: 12 set. 2017.

VALENTE, Leo. Cachorro sarnento incomoda moradores no Andaiá. Blog do Valente. Santo Antonio de Jesus. 2011. Disponível em: <http://blogdovalente.com.br/sem-categoria/2011/01/cachorro-sarnento-incomoda-moradores-noandaia/>. Acesso em: 07 nov. 2017.

WATANABE, Phillippe. Chimpanzé argentina ganha habeas corpus e vai para santuário em SP. Folha de São Paulo. Sorocaba. 2017. Ambiente. Disponível em: <http://www1.folha.uol.com.br/ambiente/2017/04/1873048-chimpanzeargentina-ganha-habeas-corpus-e-vai-para-santuario-em-sp.shtml>. Acesso em: 21 out. 2017.

2014. 